\title{
Combinatorial Effects of Organophosphate (Temephos), Glyphosate (Roundup) and Sodium Dodecil Sulfate (Sds) on Zebrafish (Danio Rerio) Gills: A Morphometric and Histological Study
}

Thamyris Santos-Silva

UFSJ: Universidade Federal de Sao Joao del-Rei

Rosy I. M. A. Ribeiro

UFSJ: Universidade Federal de Sao Joao del-Rei

Stênio N. Alves (In Memoriam)

UFSJ: Universidade Federal de Sao Joao del-Rei

Ralph G. Thomé

UFSJ: Universidade Federal de Sao Joao del-Rei

Hélio Santos ( $\square$ hbsantos@ufsj.edu.br)

UFSJ: Universidade Federal de Sao Joao del-Rei https://orcid.org/0000-0001-6813-8522

\section{Research Article}

Keywords: fish gills, lamellar fusion, pesticides, circulatory disturbances, surfarctants

Posted Date: February 15th, 2021

DOI: https://doi.org/10.21203/rs.3.rs-185080/v1

License: (c) (i) This work is licensed under a Creative Commons Attribution 4.0 International License.

Read Full License 


\section{Abstract}

Pesticides, as Temephos and Roundup, and surfactants, like Sodium Dodecyl Sulfate (SDS), when dicharged into the environment, are harmful to non-target wildlife, especially fish. To evaluate the effects of those chemicals alone and their binary combinations, we assessed the histological alterations in Danio rerio gills after 15 days of exposure to Temephos (1ppm), Roundup (10ppm), SDS (2ppm), SDS plus Temephos (2ppm+1ppm), SDS plus Roundup (2ppm+10ppm) and Temephos plus Roundup $(1 \mathrm{ppm}+10 \mathrm{ppm})$. Hyperplasia, a regressive change, was significant in all exposed groups. The progressive change, complete fusion of lamellae, was significantly intensive in Roundup plus Temephos group. Regarding to circulatory disturbances, vascular congestion was significant intensive in SDS group, while severe aneurysm was observed in Roundup group. Although xenobiotics in the blend are biologically complex, mainly for long periods, combinatorial exposure incremented only complete lamellar fusion. Our results reinforce the rationalization of indiscriminate use of those compounds alone or in combination.

\section{Introduction}

Pesticides are chemicals widely used in agriculture for the control of pests, such as insects and weeds. Despite their impact on productivity and economy, when misused, these agents can contaminate soil and water (Li 2018; Woodrow et al. 2018). Since most formulations still applied in crops are not specific for pests, their compounds can directly or indirectly affect the structure and biological function of non-target organisms, such as amphibians and fishes (Annett et al. 2014; Corbett et al. 2014).

Among the most reported pesticides worldwide are organophosphate insecticides and herbicides. Within the first group, Temephos, an organophosphorus pesticide, is classified as slight toxic product (category III) by United States of Environmental Protection Agency (US EPA). It is absorbed by inhalation, ingestion or skin contact (Fersol 2010). Temephos inhibits the enzyme acetylcholinesterase (AChE) in central and peripheral nervous systems, leading to accumulation of acetylcholine, causing death by respiratory depression (Aiub et al. 2002). However, it is not specific for insects, hence being highly toxic and prejudicial to non-target species inadequately exposed (Ba-Omar et al. 2011). The relatively low cost, easy manipulation and safe storage at tropical climates make Temephos an attractive pesticide for programs of insect control (Edward and Sogbesan 2007). In Brazil, the agrochemical still has been used to control disease vectors, such as Aedes aegypti (Valle et al. 2019).

Regarding the herbicides, Roundup is a water-soluble glyphosate and has been used in agriculture to control pragues. It is classified by the US EPA as a moderate acute toxic compound (category III) (MONSANTO 2014). Roundup is a competitive inhibitor of the enzyme 5-enolpyruvyl-shikimate-3phosphate synthase, which participates in the synthesis of essential aromatic amino acids in plants (Steinrücken and Amrhein 1980). Contrary to this classification, there are several non-targets for glyphosates, notably marine species (Sancho et al. 2000; Bridi et al. 2017; Rodrigues et al. 2017). 
Anionic surfactants are the most important surfactant used in cleaning products, as well as in commercial formulation of pesticide to reduce surface tension and improve surface spreading. They are classified by US EPA as toxic substance control act since these products may present an unreasonable risk of injury to health or the environment. Anionic surfactants are commonly released in the environment, polluting sewage, and presenting potential toxicity to water, soil and biota (Rosety-Rodríguez et al. 2002). Sodium Dodecyl Sulfate (SDS), a widely used surfactant, is an anionic detergent applied from industrial purposes to household cleaning products (Rowe et al. 2009). Considered safe for humans, SDS has equally important toxic effects in aquatic organisms (Messina et al. 2014; Rodrigues et al. 2015; Santos et al. 2016; Sayed and Authman 2018).

Fishes represent a population commonly affected by these agents, that are found as residues contaminating domestic and industrial sewage, inadequately discharged in aquatic ecosystems (Sales et al. 2017). Aquatic organisms are exposed simultaneously to a mixture of pesticides, since in agriculture practices it is common the application of more than one pesticide and subsequently, they are discharged in the environmental at the same time (Van Den Brink et al. 2002; Santos and Martinez 2014). Therefore, when Temephos, Roundup and SDS are released in the environment, they may interact among themselves and lead to different reactions, which can include additive, synergistic or antagonistic effects. Danio rerio, also known as zebrafish, is a freshwater fish widely used to evaluate toxicity, since it is sensitive to pollutants. Indeed, several studies have reported that morphological and behavioral alterations found in zebrafish exposed to pesticides are good biomarkers for evaluating environmental conditions and water quality (Schmidel et al. 2014; Bridi et al. 2017; Macirella and Brunelli 2017).

Gills are organs exposed to these contaminants and are responsible for hematosis, osmoregulation, nutrient uptake and neuronal signaling (Bernet et al. 1999). These organs are extensively vascularized, with a large surface area covered by squamous epithelium in direct contact with water (Winkaler et al. 2008). Although numerous organs, such as eyes, gills and skin, are in directly contact with water, gills are the first organ to elicit structural and functional responses (Bernet et al. 1999). The morphological adaptive modifications in gills follow exposure to these agents represents a set of pathological alterations, which are commonly used as parameters to evaluate toxicological studies, water quality and environmental impacts related to human activities (Sales et al. 2017; Oliveira et al. 2018; Macedo et al. 2020; Muthukumaravel et al. 2020).

Histological alterations may be classified according to their reaction patterns, which include different types of morphological changes, namely progressive changes, regressive changes, and circulatory disturbance. A typical progressive change is hyperplasia, consisting of tissue enlargement caused by cell growth, but without variations in cellular volume. Regressive changes, such as epithelial lifting atrophy and necrosis are more severe and can impair the proper function of organs. Circulatory disturbances consist in blood and interstitial fluid imbalances, including blood congestion, aneurysm and hemorrhage (Bernet et al. 1999; Sales et al. 2017). 
Temephos, Roundup and SDS have been evaluated separately, but aquatic organisms are exposed to diverse xenobiotics at the same time. Superficial and subaquatic contaminants reach the environment concomitantly and hence their effects upon non-target organisms could superimpose (Santos and Martinez 2014). Thus, this study was investigating and quantifying the histological progressive, regressive changes and circulatory disturbances in gills of $D$. rerio exposed to Temephos, Roundup, SDS and their binary combinations.

\section{Material And Methods}

\section{Zebrafish care}

The 28 adult $D$. rerio specimens were purchased locally from a commercial fish store. Animals were acclimated for one week, distributed in seven $3 \mathrm{~L}$ glass aquaria filled with tap water from COPASA (Sanitation Department of the State of Minas Gerais) ( $n=4$ fish per tank). The low density per aquarium had as the goal provide the welfare to animals during the experiment as described for the zebrafish maintaining (Reed and Jennings 2011). Water dechlorinated was previously treated with a conditioner called the Prime ${ }^{\circledR}$ from Seachem Laboratories that was used to eliminate the chlorine, chloramine, and ammonia. During the experiment, water was maintained at $26^{\circ} \mathrm{C}$, constant oxygenation, $\mathrm{pH}=6.8$, controlled photoperiod $(14 / 10 \mathrm{~h})$ and fishes were fed twice a day with commercial food from Alcon Basic ${ }^{\circledR}$. All procedures were performed following the ethical principles established by Animal Use Ethics Committee, Federal University of São João del-Rei, protocol 23/2012. Animal handling and laboratory procedures were conducted according to the Guidance on the housing and care of zebrafish (Reed and Jennings 2011).

\section{Experimental design}

Temephos 1G® (Fersol) concentration used was based on the guidelines of National Dengue Control Program in Brazil (Brasil 2009). Roundup Original® (Monsanto) the concentration was chosen due to on the upper limit of glyphosate (3.7 ppm) accepted for water bodies with no intercepting vegetation (Langiano and Martinez 2008). SDS (High purity) concentration used was based on average values found in industrial and domestic sewage from Southeast and South regions from Brazil (Vicente 2004; Bohn 2014).

After acclimation, each group was exposed to: Temephos 1 ppm; Roundup 10 ppm; SDS 2 ppm; SDS plus Temephos (2 ppm + 1 ppm); SDS plus Roundup ( $2 \mathrm{ppm}+10 \mathrm{ppm})$; Temephos plus Roundup (1 ppm + 10 $\mathrm{ppm}$ ); control group. The experiment was carried out for 15 days in static system according to ToledoIbarra et al. (2018). During the experiment, there was no died fish.

\section{Histology}

After treatments, all animals were euthanized with a lethal dose of benzocaine (50 $\left.\mathrm{mgL}^{-1}\right)$. Gills were collected and fixed in Bouin's liquid for $24 \mathrm{~h}$. Samples were submitted to routine histological techniques, 
embedded in paraffin, and Sect. $6 \mu \mathrm{m}$ thickness were stained with hematoxylin-eosin (H\&E) as described in Sales et al. (2017).

\section{Morphometry}

Morphometry was performed for all slides, counting 12 gill filaments per sample. Filaments were photographed using light microscopy (Zeiss Primo Star) (20X magnification) that was coupled with Axiovision 4.8 software. After histological analyses, an occurrence score was established to rank the lesions that were identified in gills from treatment groups, according to Albinati et al. (2009): 0 - alteration not observed; 1 - discrete (up to two occurrences); 2 - moderate (three to five occurrences); 3 - severe (more than five occurrences).

These occurrence scores were used to calculate the median score of histological changes for each group, in which were classified as discrete (0 to 1.0 ), moderate (1.1 to 2.0 ) or severe (2.1 to 3.0 ).

\section{Statistical analysis}

The Kolmogorov-Smirnov test was used to assess the normality of data and then, the data were analyzed by non-parametric Kruskal-Wallis test followed by the Dunn's post-hoc test. Values were expressed as median and (interquartile range). Statistical significance was assumed for $p<0.05$. Graphs were plotted in a box and whisker chart with min and max values. All tests were performed using Graph Pad Prisma, version 5.00 (Graph Pad Software, San Diego, CA, USA).

\section{Results}

\section{Histological changes in exposed gills}

Gills from control group displayed a typical histological architecture (Fig. 1A). The primary lamellae (PL) presented normal squamous epithelium with several cell types, such as mucous cells and mitochondriarich cells. Hyaline cartilage sustaining PL and a central venous sinus were also recorded. Secondary lamellae (SL) were supported by pillar cells and covered with simple squamous epithelium and supported by pillar cells.

Progressive, regressive changes and circulatory disturbances were observed in all gills exposed to treatments (Fig. 1B - F). Progressive changes as hyperplasia of secondary lamellae (HSL) were found on $S L$ in all treated groups. Epithelial lifting (EL), a regressive change was also detected (Fig. 1B), as well incomplete fusion of secondary lamellae (IFL) and complete fusion of secondary lamellae (CFL) (Fig. 1F). Circulatory disturbances characterized by vascular congestion (VC) in central venous sinus (Fig. 1E and F) and aneurysm (AN) (Fig. 1D) were also present in all exposed groups. In addition, regions of necrosis mainly in secondary lamella (Fig. 1C) and hemorrhage (Fig. 1D) were also identified for all treatments, at least in one animal. Table 1 summarize the classification of histological changes in gills of D. rerio exposed to Temephos, Roundup, SDS alone and their combinations. 
Table 1

Classification of histological changes in zebrafish gills exposed to Temephos, Roundup, SDS and their combinations.

\begin{tabular}{|lllll|}
\hline \multirow{2}{*}{ Group } & Progressive & Regressive & Circulatory disturbances \\
\cline { 2 - 5 } & HSL & CFL & VC & AN \\
\hline Control & Discrete & Discrete & Discrete & Discrete \\
\hline Temephos & Severe & Moderate & Moderate & Moderate \\
\hline Roundup & Severe & Severe & Moderate & Severe \\
\hline SDS & Severe & Moderate & Severe & Discrete \\
\hline SDS + Temephos & Severe & Moderate & Moderate & Moderate \\
\hline SDS + Roundup & Severe & Moderate & Moderate & Moderate \\
\hline Temephos + Roundup & Severe & Severe & Moderate & Moderate \\
\hline
\end{tabular}

\section{Morphometric analysis}

After histological analysis exploratory from gills, the following parameters were chosen and measured in the experimental groups: epithelial lifting, hyperplasia of secondary lamellae, incomplete fusion of secondary lamellae, complete fusion of secondary lamellae, vascular congestion and aneurysm.

\section{Progressive changes}

All exposed gills displayed HSL (Fig. 2), with a median 0.5 (1.0). Animals exposed to Temephos, Roundup, SDS, Temephos plus SDS and Roundup plus SDS presented maxima median scores 3.0 (0.0), indicating severe alterations. For Temephos plus Roundup, the observed score was 2.5 (1.0). When compared to control, all median scores for treatments were significantly higher, indicating association between HSL and exposure to tested xenobiotics.

\section{Regressive changes}

For all exposed groups, no differences between mean scores of EL and IFL were found, when compared to control (data not shown). Only animals exposed to Temephos + Roundup presented a significant higher median score for CLF (3.0 (2.0)), when compared to control (0.0 (1.0)) (Fig. 3). Temephos and Roundup groups had median CLF scores of 1.0 (1.0) and 2.5 (2.0), respectively. In those groups, CLF were classified as severe. Gills exposed to the SDS presented a discrete CLF (1.5 (1.0)). SDS + Temephos also displayed discrete median CLF score (1.0 (1.0)), whereas SDS + Roundup group had a moderate median score for CLF (2.0 (0.0)). Despite this trend, combination of SDS with pesticides showed no significant differences in CLF mean scores when compare to control.

\section{Circulatory disturbances}


Moderate VC was visualized in gills exposed to Temephos, Roundup, SDS + Temephos and SDS + Roundup (1.5 (1.0); 2.0 (2.0); 2.0 (0.0); 2.0 (0.0), respectively). Temephos + Roundup group also displayed moderate VC $(2.0(0.0))$. Severe VC was observed only for SDS $(2.0(1.0)$, a median score significantly higher than control (1.0 (1.0) (Fig. 4A). AN in control had a median score of 0.0 (1.0) (Fig. 4B). Roundup displayed a median score $(3.0(1.0))$ classified as severe, significantly higher than control. Despite the moderate-to-discrete mean AN scores for all other groups (Temephos, 1.0 (3.0); SDS, 1.0 (0.0); SDS + Temephos, 2.0 (0.0); SDS + Roundup, 2.0 (0.0)); Temephos + Roundup, 1.0 (1.0)), no statistical differences were found when comparing them to control.

\section{Discussion}

Histological changes in gills have been described in wild fishes (Sales et al. 2017) or during acute exposure to pesticides under controlled conditions, since these organs are extremely exposed to environment and serve as entrance for contaminants (Macirella and Brunelli 2017). Organophosphates, such as Temephos, were developed to kill target parasites, without any damage to the host and other nontarget organisms in the environment, where the insecticide is dispersed. However, undesirable effects on non-target organisms have been reported in varying degrees for Temephos (Sarikaya and Yilmaz 2003). Pathological findings associated to Temephos exposure are not exclusive to gills, but also found in liver, muscles and nerve tissue (Guimarães et al. 2007; Jayasundara and Pathiratne 2008; Ba-Omar et al. 2011; Santos et al. 2016). Moreover, organophosphates also can induce morphological and biochemical abnormalities in exposed amphibians (Ma et al. 2019; Rutkoski et al. 2020).

In this study, hyperplasia of secondary lamellae (HSL) was the most striking alteration found in zebrafish gills exposed to Temephos. Moderate occurrences of complete lamellae fusion (CLF) and circulatory disturbances were visualized. Epithelium lifting (EPL), HSL and lamellar fusion are defense responses induced by Temephos. Probably, to prevent the diffusion of Temephos through gills, HSL led to lamellar fusion. As result of stress response, reduction of gill surface area decreases the oxygen availability and increases the diffusion distance of external environment and vascular system (Ba-Omar et al. 2011). Indeed, the teleost Anphanius dispar, when exposed to Temephos, also developed degeneration of gill tissues, such as supporting cartilage, epithelial hypertrophy, decrease of mitochondria-rich cells and EPL (Ba-Omar et al. 2011). The same histological alterations also were found in Oreochromis niloticus when exposed to other organophosphates as trichlorfon and fention (Guimarães et al. 2007; Jayasundara and Pathiratne 2008).

Temephos inhibits the enzymatic activity of acetylcholinesterase (AChE), a key enzyme involved in hydrolysis of the neurotransmitter acetylcholine. In gills, the physiological role of AChE includes cell mechanisms to control the epithelium gills activity and the filtration capacity (Corsi et al. 2007). Inhibition of AChE by xenobiotics results in accumulation of acetylcholine and leads to paralysis of respiratory muscles, and subsequently compromises gill functions (Cappello et al. 2015). Interestingly, histopathological alterations found in gills were directly correlated with the inhibition of AChE follow exposure to pesticides (Guimarães et al. 2007; Jindal and Kaur 2014; Pereira and De Campos 2015; 
Doherty et al. 2016). In addition, a continuous production of reactive oxygen species (ROS) and hence oxidative stress was reported in gills of fishes exposed to different brands of organophosphates (Pham et al. 2017; Marigoudar et al. 2018).

Cellular and vascular changes in zebrafish gills exposed to Roundup confirmed those toxic effects. In fact, a higher frequency of HSL and CLF were found in gills exposed to Roundup. Circulatory disturbances were also present, and significant higher occurrence of aneurysm (AN) was found in comparison with control group, but vascular congestion (VC) was classified as moderate. The AN have pathological importance, considering that they are usually irreversible and can progress to hemorrhage if the environmental conditions are not altered (Sales et al. 2017). Acute exposure to Roundup (96 h) also causes oxidative stress and DNA damage in gills of Corbicula fluminea (Santos and Martinez 2014). The toxic effects of Roundup on gill cells were also demonstrated for different fish species and diverse concentrations of the xenobiotic (Ramírez-Duarte et al. 2008; Albinati et al. 2009; Hued et al. 2012). Moreover, Roundup can also lead to histopathological alterations in distinct fish organs, such as brain, skin, liver and kidney (Albinati et al. 2009; Ramírez-Duarte et al. 2008; Rodrigues et al. 2017). Among the widely variety of non-target species, amphibians are particularly sensitive to environmental exposure of glyphosates (Annett et al. 2014).

Glyphosates, as Roundup, target the enzyme EPSP, which interrupts the synthesis of aromatic amino acids in plants. Although this pathway is not present in animals, several evidences have showed that aquatic organisms are susceptible to glyphosate effects, mainly by oxidative stress and AChE alterations. When biotransformed, the compound alters the oxidative balance of zebrafish gills. In this sense, Temephos and Roundup induce production of ROS and reduces gill redox buffering capacity and tissue damage (De Menezes et al. 2011; Santos and Martinez 2014; Velasques et al. 2016; Lopes et al. 2017). Furthermore, genotoxic effects of glyphosates have already reported in fishes (Modesto and Martinez 2010; Santos and Martinez 2014). Interestingly, inhibition of AChE is also a possible mechanism of action observed in herbicides (Lopes et al. 2017; Modesto and Martinez 2010; Sancho et al. 2000).

In this study, treatment with SDS appeared to cause HSL and VC in zebrafish gills. Regarding the latter, intravenous sinus congestion is an injury that leads to functional damage, being classified as reversible, in case of improvement in water quality, or progressive, in cases of persistent exposure (Albinati et al. 2009; Sales et al. 2017). Similar results were reported in gills from Scophthalmus maximus $L$ exposed to SDS (Rosety-Rodríguez et al. 2002) and in Astyanax altiparanae and Prochilodus lineatus submitted to biodegradable detergents (Pereira and De Campos 2015).

The toxic effects of SDS in fishes are correlated with the reduction of surface tension, leading to less oxygen dissolved in water and gas absorption by gills (Rosety-Rodríguez et al. 2002). Moreover, anionic surfactant can bind into proteins, DNA or into cell fragments, which led to disturbances in cell function. This capability of SDS to enter in cell membranes and to bind in cell fragments can also increase generation of reactive species of oxygen, which cause tissue damage (Messina et al. 2014). Regarding AChE inhibition, evidences suggest that SDS have no significantly effect in the in vivo enzymatic activity 
of exposed fishes (Nunes et al. 2005; Rodrigues et al. 2011; Ramos et al. 2012; Nunes et al. 2016), whereas SDS exposure was responsible for in vitro inhibitory effects in exposed fish organs and in sensitive aquatic organisms (Guilhermino et al. 2000; Nunes et al. 2005; Feng et al. 2008).

Anionic surfactants, such as SDS, are add to commercial formulation of pesticides to enhance their diffusion through plants. Cuhra and colls (2013) suggested that the toxic effects of Roundup may be derived from synergistic effects of glyphosate and adjuvants. In contrast, Bridi and colls (2017) demonstrated that there are small differences in morphological and behavioral parameters of zebrafish exposed to glyphosate and Roundup formulation. Indeed, active ingredients of pesticides, commercial formulation of pesticides and detergents are extremely harmful to aquatic organisms. Since fishes are exposed to diverse xenobiotics at the same time, we aimed to evaluate the combinatorial effects of Temephos, Roundup and SDS, based in concentrations observed in the natural environment. Therefore, the binary combinations of these agents represent the superficial and subaquatic contaminants that reach the environment concomitantly.

Considering the combinatorial effects of Temephos plus SDS, Roundup plus SDS and Temephos plus Roundup, the most common alteration observed were HSL. Although moderate circulatory disturbances were observed in all associations, Temephos plus SDS exposure displayed widespread areas of necrosis with hemorrhage that was observed in at least one animal per exposed group. Necrosis has been characterized by disruption of plasma membrane, release of cytoplasmic material and intense inflammatory reaction (Rock and Kono 2008). In agreement with these results, necrosis, hemorrhage and inflammatory infiltrate were also observed in gills exposed to SDS or Roundup (Rosety-Rodríguez et al. 2002; Ramírez-Duarte et al. 2008). Necrosis epithelial also was observed in secondary lamellae from Cirrhinus mrigala exposed to $0.91 \mathrm{ppm}$ and $1.82 \mathrm{ppm}$ concentrations of dichlorvos, an organophosphate pesticide, for 10 days treatment (Velmurugan et al. 2009). In fact, theses histopathological parameters describe in $D$. rerio gills after exposure to Roundup and SDS have been used widely in several research fields including as biomarker tools in environmental monitoring using fish as bioindicators (Pereira and De Campos 2015; Sales et al. 2017)

Maybe the reduction of the exposure period could be necessary for a better assessment of combinatorial effects of tested compounds, as well the use of lower concentrations, to adequately identify synergistic interaction of pesticides and surfactants in mixture. Notably, Santos and Martinez (2014) observed antagonistic effects for the co-administration of atrazine, an herbicide, and Roundup, when evaluating biotransformation and oxidative stress. On the other hand, a more in-dept analysis must be performed for better identification of potential antagonist effects in gills exposed to combinations of Temephos, Roundup and SDS.

\section{Conclusion}

In conclusion, adaptive changes found in zebrafish gills that are caused by Temephos, Roundup and SDS, alone or in combination, reflect the toxic effects of these agents. Considering that interactions 
between xenobiotics present in a given mixture are biologically complex, especially for long exposure periods, no significant increment in the incidence of histological alterations was observed when comparing associations to single treatments. However, it is important to note that concentrations of Temephos, Roundup and SDS used here were based on environmental findings. Our results reinforce the need for a more rational and controlled use and disposal of herbicides and surfactants, since their persistent presence as environmental contaminants appears to be deleterious to non-target organisms such as fishes.

\section{Declarations}

Ethics approval and consent to participate: Not Applicable

Consent for publication: Not Applicable

Availability of data and materials: Not Applicable

Competing interests: The authors declare that they have no competing interests.

Funding: This work was supported by a Fundação de Amparo a Pesquisa

do Estado de Minas Gerais (FAPEMIG) (CVZ-APQ-03548-16) and CNPq (process 405822 / 2016-2) grants to H.B.S..

\section{Authors' contributions:}

RGT and HBS: Conception and experimental design and grants to research;

TSS, RGT, RIMAR, SNA and HBS: Data analysis and paper draft;

\section{Acknowledgments}

we are most grateful for the financial support of FAPEMIG, concession number CVZ_APQ-03548- 16.; and the grant number of the CNPq (process 405822 / 2016-2). We would also like to thank the Tissue Processing Laboratory (LAPROTEC) for the equipment, materials and support for research.

\section{References}

1. Aiub CAF, Coelho ECA, Sodré E, Pinto LFR, Felzenszwalb I (2002) Genotoxic evaluation of the organophosphorous pesticide temephos. Genet Mol Res. 1(2):159-166.

2. Albinati ACL, Moreira ELT, Albinati RCB, Carvalho JV, Lira AD de, Santos GB, Vidal LVO (2009) Biomarcadores histológicos: toxicidade crônica pelo Roundup em piauçu (Leporinus macrocephalus). Arq Bras Med Veterinária e Zootec. 61(3):621-627. 
3. Annett R, Habibi HR, Hontela A (2014) Impact of glyphosate and glyphosate-based herbicides on the freshwater environment. J Appl Toxicol. 34(5):458-479.

4. Ba-Omar TA, Al-Jardani S, Victor R (2011) Effects of pesticide temephos on the gills of Aphanius dispar (Pisces: Cyprinodontidae). Tissue Cell. 43(1):29-38.

5. Bernet D, Schmidt H, Meier W, Burkhardt-Holm P, Wahli T (1999) Histopathology in fish: proposal for a protocol to assess aquatic pollution. J Fish Dis. 22(1):25-34.

6. Bohn FP (2014)Tratamento do efluente gerado na lavagem de veículos.: Universidade Regional do Noroeste do Estado do Rio Grande do Sul.

7. Brasil M da S (2009) Diretrizes Nacionais para a Prevenção e Controle de Epidemias de Dengue. 1st ed. Pro-ed, editor. Brasília, DF.

8. Bridi D, Altenhofen S, Gonzalez JB, Reolon GK, Bonan CD (2017) Glyphosate and Roundup ${ }^{\circledR}$ alter morphology and behavior in zebrafish. Toxicology. 392(October):32-39.

9. van den Brink PJ, Hartgers EM, Gylstra R, Bransen F, Brock TCM (2002) Effects of a mixture of two insecticides in freshwater microcosms: II. Responses of plankton and ecological risk assessment. Ecotoxicology. 11(3):181-197.

10. Cappello T, Maisano M, Giannetto A, Parrino V, Mauceri A, Fasulo S (2015) Neurotoxicological effects on marine mussel Mytilus galloprovincialis caged at petrochemical contaminated areas (eastern Sicily, Italy):1H NMR and immunohistochemical assays. Comp Biochem Physiol Part - C Toxicol Pharmacol. 169:7-15.

11. Corbett PA, King CK, Stark JS, Mondon JA (2014) Direct evidence of histopathological impacts of wastewater discharge on resident Antarctic fish (Trematomus bernacchii) at Davis Station, East Antarctica. Mar Pollut Bull. 87(1):48-56.

12. Corsi I, Pastore AM, Lodde A, Palmerini E, Castagnolo L, Focardi S (2007) Potential role of cholinesterases in the invasive capacity of the freshwater bivalve, Anodonta woodiana (Bivalvia: Unionacea): A comparative study with the indigenous species of the genus, Anodonta sp. Comp Biochem Physiol - C Toxicol Pharmacol. 145(3):413-419.

13. Cuhra M, Traavik T, Bøhn T (2013) Clone- and age-dependent toxicity of a glyphosate commercial formulation and its active ingredient in Daphnia magna. Ecotoxicology. 22(2):251-262.

14. Doherty VF, Ladipo MK, Aneyo IA, Adeola A, Odulele WY (2016) Histopathological alterations, biochemical responses and acetylcholinesterase levels in Clarias gariepinus as biomarkers of exposure to organophosphates pesticides. Environ Monit Assess. 188(5):312-322.

15. Edward JB, Sogbesan OA (2007) Toxicity Effect of Temephos on Bulinus globossus and Lymnaea natalensis. Adv Biol Res (Rennes). 1(3-4):130-133.

16. Feng T, Li ZB, Guo XQ, Guo JP (2008) Effects of trichlorfon and sodium dodecyl sulphate on antioxidant defense system and acetylcholinesterase of Tilapia nilotica in vitro. Pestic Biochem Physiol. 92(3):107-113.

17. Fersol (2010) Temefós $1 \mathrm{G}$ - Ficha de Informações de Segurança de Produto Químico. (2):1-9. 
18. Guilhermino L, Lacerda MN, Nogueira AJA, Soares AMVM (2000) In vitro and in vivo inhibition of Daphnia magna acetylcholinesterase by surfactant agents: Possible implications for contamination biomonitoring. Sci Total Environ. 247(2-3):137-141.

19. Guimarães ATB, Silva de Assis HC, Boeger W (2007) The effect of trichlorfon on acetylcholinesterase activity and histopathology of cultivated fish Oreochromis niloticus. Ecotoxicol Environ Saf. 68(1):57-62.

20. Hued AC, Oberhofer S, De Los Ángeles Bistoni M (2012) Exposure to a commercial glyphosate formulation (Roundup) alters normal gill and liver histology and affects male sexual activity of Jenynsia multidentata (Anablepidae, cyprinodontiformes). Arch Environ Contam Toxicol. 62(1):107117.

21. Jayasundara VK, Pathiratne A (2008) Effect of repeated application of fenthion as a mosquito larvicide on Nile tilapia (Oreochromis niloticus) inhabiting selected water canals in Sri Lanka. Bull Environ Contam Toxicol. 80(4):374-377.

22. Jindal R, Kaur M (2014) Acetylcholinesterase inhibition and assessment of its recovery response in some organs of Ctenopharyngodon idellus induced by chlorpyrifos. Int J Sci Environ Technol. $3(2): 473-480$.

23. Langiano V do C, Martinez CBR (2008) Toxicity and effects of a glyphosate-based herbicide on the Neotropical fish Prochilodus lineatus. Comp Biochem Physiol - C Toxicol Pharmacol. 147(2):222231.

24. Li Z (2018) A health-based regulatory chain framework to evaluate international pesticide groundwater regulations integrating soil and drinking water standards. Environ Int. 121(2):1-26.

25. Lopes FM, Caldas SS, Primel EG, da Rosa CE (2017) Glyphosate Adversely Affects Danio rerio Males: Acetylcholinesterase Modulation and Oxidative Stress. Zebrafish. 14(2):97-105.

26. Ma Y, Li B, Ke Y, Zhang YH (2019) Effects of low doses Trichlorfon exposure on Rana chensinensis tadpoles. Environ Toxicol. 34(1):30-36.

27. Macêdo A KS, Dos Santos KPE, Brighenti LS, Windmöller CC, Barbosa FAR, Ribeiro RIMA, Santos HB, Thomé RG (2020) Histological and molecular changes in gill and liver of fish (Astyanax lacustris Lütken, 1875) exposed to water from the Doce basin after the rupture of a mining tailings dam in Mariana, MG, Brazil. Sci Total Environ, 139505.

28. Macirella R, Brunelli E (2017) Morphofunctional alterations in zebrafish (Danio rerio) gills after exposure to mercury chloride. Int J Mol Sci. 18(4):1-19.

29. Marigoudar SR, Mohan D, Nagarjuna A, Karthikeyan P (2018) Biomarker and histopathological responses of Lates calcarifer on exposure to sub lethal concentrations of chlorpyrifos. Ecotoxicol Environ Saf. 148(June):327-335.

30. Menezes CC, Da Fonseca MB, Loro VL, Santi A, Cattaneo R, Clasen B, Pretto A, Morsch VM (2011) Roundup effects on oxidative stress parameters and recovery pattern of Rhamdia quelen. Arch Environ Contam Toxicol. 60(4):665-671. 
31. Messina CM, Faggio C, Laudicella VA, Sanfilippo M, Trischitta F, Santulli A (2014) Effect of sodium dodecyl sulfate (SDS) on stress response in the Mediterranean mussel (Mytilus Galloprovincialis): Regulatory volume decrease (Rvd) and modulation of biochemical markers related to oxidative stress. Aquat Toxicol. 157:94-100.

32. Modesto KA, Martinez CBR (2010) Roundup ${ }^{\circledR}$ causes oxidative stress in liver and inhibits acetylcholinesterase in muscle and brain of the fish Prochilodus lineatus. Chemosphere. 78(3):294299.

33. MONSANTO (2014) Roundup. Ficha de Informações de Segurança de Produto Químico. 1-17.

34. Muthukumaravel K, Vasanthi N, Stalin A, Alam L, Santhanabharathi B, Musthafa MS (2020) Sublethal effects of phenol on histology of selected organs of freshwater fish Mystus vittatus. Environ Sci Pollut Res. 1-9.

35. Nunes B, Carvalho F, Guilhermino L (2005) Characterization and use of the total head soluble cholinesterases from mosquitofish (Gambusia holbrooki) for screening of anticholinesterase activity. J Enzyme Inhib Med Chem. 20(4):369-376.

36. Nunes B, Miranda MT, Correia AT (2016) Absence of effects of different types of detergents on the cholinesterasic activity and histological markers of mosquitofish (Gambusia holbrooki) after a sublethal chronic exposure. Environ Sci Pollut Res. 23(15):14937-14944.

37. Pereira BB, De Campos EO (2015) Enzymatic Alterations and Genotoxic Effects Produced by Sublethal Concentrations of Organophosphorous Temephos in Poecilia reticulata. J Toxicol Environ Heal - Part A Curr Issues. 78(16):1033-1037.

38. Pham B, Miranda A, Allinson G, Nugegoda D (2017) Evaluating the non-lethal effects of organophosphorous and carbamate insecticides on the yabby (Cherax destructor) using cholinesterase (AChE, BChE), Glutathione S-Transferase and ATPase as biomarkers. Ecotoxicol Environ Saf. 143(January):283-288.

39. Ramírez-Duarte W, Rondón-Barrgán I, Eslva-Mocha P (2008) Acute toxicity and histopathological alterations of Roundup ${ }^{\circledR}$ herbicide on "cachama blanca" (Piaractus brachypomus). Pesq Vet Bras. 28(11):547-554.

40. Ramírez-Duarte WF, Rondón-Barragán IS, Eslava-Mocha PR (2008) Toxicidade aguda e alterações histopatológicas induzidas pelo herbicida Roundup ${ }^{\circledR}$ em pirapitinga (Piaractus brachypomus). Pesqui Vet Bras. 28(11):547-554.

41. Ramos AS, Gonçalves F, Antunes SC, Nunes B (2012) Cholinesterase characterization in Corbicula fluminea and effects of relevant environmental contaminants: A pesticide (chlorfenvinphos) and a detergent (SDS). J Environ Sci Heal - Part B Pestic Food Contam Agric Wastes. 47(6):512-519.

42. Reed $B$, Jennings $M(2011)$ Guidance on the housing and care of Zebrafish Danio rerio. Res Anim Dep Sci Group, RSPCA.(May):1-27.

43. Rock, Kenneth L; Kono H (2008) The Inflammatory Response to Cell Death. Annu Rev Pathol Dis. 3:67-97. 
44. Rodrigues L de B, de Oliveira R, Abe FR, Brito LB, Moura DS, Valadares MC, Grisolia CK, de Oliveira DP, de Oliveira GAR (2017) Ecotoxicological assessment of glyphosate-based herbicides: Effects on different organisms. Environ Toxicol Chem. 36(7):1755-1763.

45. Rodrigues S, Correia AT, Antunes SC, Nunes B (2015) Alterations in gills of Lepomis gibbosus, after acute exposure to several xenobiotics (pesticide, detergent and pharmaceuticals): Morphometric and biochemical evaluation. Drug Chem Toxicol. 38(2):126-132.

46. Rodrigues SR, Caldeira C, Castro BB, Gonçalves F, Nunes B, Antunes SC (2011) Cholinesterase (ChE) inhibition in pumpkinseed (Lepomis gibbosus) as environmental biomarker: ChE characterization and potential neurotoxic effects of xenobiotics. Pestic Biochem Physiol. 99(2):181-188.

47. Rosety-Rodríguez M, Ordoñez FJ, Rosety M, Rosety JM, Rosety I, Ribelles A, Carrasco C (2002) Morpho-histochemical changes in the gills of turbot, Scophthalmus maximus L., induced by Sodium Dodecyl Sulfate. Ecotoxicol Environ Saf. 51(3):223-228.

48. Rowe R, Sheskey P, Quinn M (2009) Handbook of Pharmaceutical Excipients. Handb Pharm excipients, Sixth Ed.:549-553.

49. Rutkoski CF, Macagnan N, Folador A, Skovronski VJ, do Amaral AMB, Leitemperger J, Costa MD, Hartmann PA, Müller C, Loro VL, Hartmann MT (2020) Morphological and biochemical traits and mortality in Physalaemus gracilis (Anura: Leptodactylidae) tadpoles exposed to the insecticide chlorpyrifos. Chemosphere. 250:126162.

50. Sales CF, Santos KPE dos, Rizzo E, Ribeiro RIM de A, Santos HB dos, Thomé RG (2017) Proliferation, survival and cell death in fish gills remodeling: From injury to recovery. Fish Shellfish Immunol. 68:10-18.

51. Sancho E, Cerón JJ, Ferrando MD (2000) Cholinesterase activity and hematological parameters as biomarkers of sublethal molinate exposure in Anguilla anguilla. Ecotoxicol Environ Saf. 46(1):81-86.

52. Santos HB dos, Vieira L, Alves SN, Thomé RG (2016) Análise do intestino delgado de Danio rerio exposto a organofosforado e detergente: um estudo histológico e morfométrico. Rev Conex Ciência. 11(2):51-58.

53. Santos KC dos, Martinez CBR (2014) Genotoxic and biochemical effects of atrazine and Roundup ${ }^{\circledR}$, alone and in combination, on the Asian clam Corbicula fluminea. Ecotoxicol Environ Saf. 100(1):714.

54. Sarikaya R, Yilmaz M (2003) Investigation of acute toxicity and the effect of 2,4-D (2,4dichlorophenoxyacetic acid) herbicide on the behavior of the common carp (Cyprinus carpio L., 1758; Pisces, Cyprinidae). Chemosphere. 52(1):195-201.

55. Sayed AEH, Authman MMN (2018) Ecotoxicology and Environmental Safety Modulatory e ff ects of green tea extract against the hepatotoxic e ff ects of 4-nonylphenol in cat fish Clarias gariepinus (Burchell, 1822). Ecotoxicol Environ Saf. 149(October):136-144.

56. Schmidel AJ, Assmann KL, Werlang CC, Bertoncello KT, Francescon F, Rambo CL, Beltrame GM, Calegari D, Batista CB, Blaser RE, et al. (2014). Subchronic atrazine exposure changes defensive 
behaviour profile and disrupts brain acetylcholinesterase activity of zebrafish. Neurotoxicol Teratol. 44:62-69. 06

57. Steinrücken HC, Amrhein N (1980) The herbicide glyphosate is a potent inhibitor of 5enolpyruvylshikimic acid-3-phosphate synthase. Biochem Biophys Res Commun. 94(4):1207-1212.

58. Toledo-Ibarra GA, Rodríguez-Sánchez EJ, Ventura-Ramón HG, Díaz-Resendiz KJG, Girón-Pérez MI (2018) Cholinergic alterations by exposure to pesticides used in control vector: Guppies fish (Poecilia reticulta) as biological model. Int J Environ Health Res. 28(1): 79-89.

59. Valle D, Bellinato DF, Viana-Medeiros PF, Lima JBP, Martins Junior ADJ (2019) Resistance to temephos and deltamethrin in aedes aegypti from Brazil between 1985 and 2017. Mem Inst Oswaldo Cruz. 114(3):1-17.

60. Velasques RR, Sandrini JZ, Da Rosa CE (2016) Roundup ® in Zebrafish: Effects on Oxidative Status and Gene Expression. Zebrafish. 13(5):432-441.

61. Velmurugan B, Selvanayagam M, Cengiz El, Unlu E (2009) Histopathological changes in the gill and liver tissues of freshwater fish, Cirrhinus mrigala exposed to dichlorvos. Brazilian Arch Biol Technol. 52(5):1291-1296.

62. Vicente J (2004) Determinação de surfactantes aniônicos em efluentes de postos revendedores de combustíveis da região da Grande Florianópolis. Universidade Federal de Santa Catarina.

63. Winkaler EU, Silva ADG, Galindo HC, Martinez CBDR (2008) Biomarcadores histológicos e fisiológicos para o monitoramento da saúde de peixes de ribeirões de Londrina, Estado do Paraná. Acta Sci Biol Sci. 23(2):507-514.

64. Woodrow JE, Gibson KA, Seiber JN (2018) Pesticides and Related Toxicants in the Atmosphere. Rev Environ Contam Toxicol. 247:147-196.

\section{Figures}




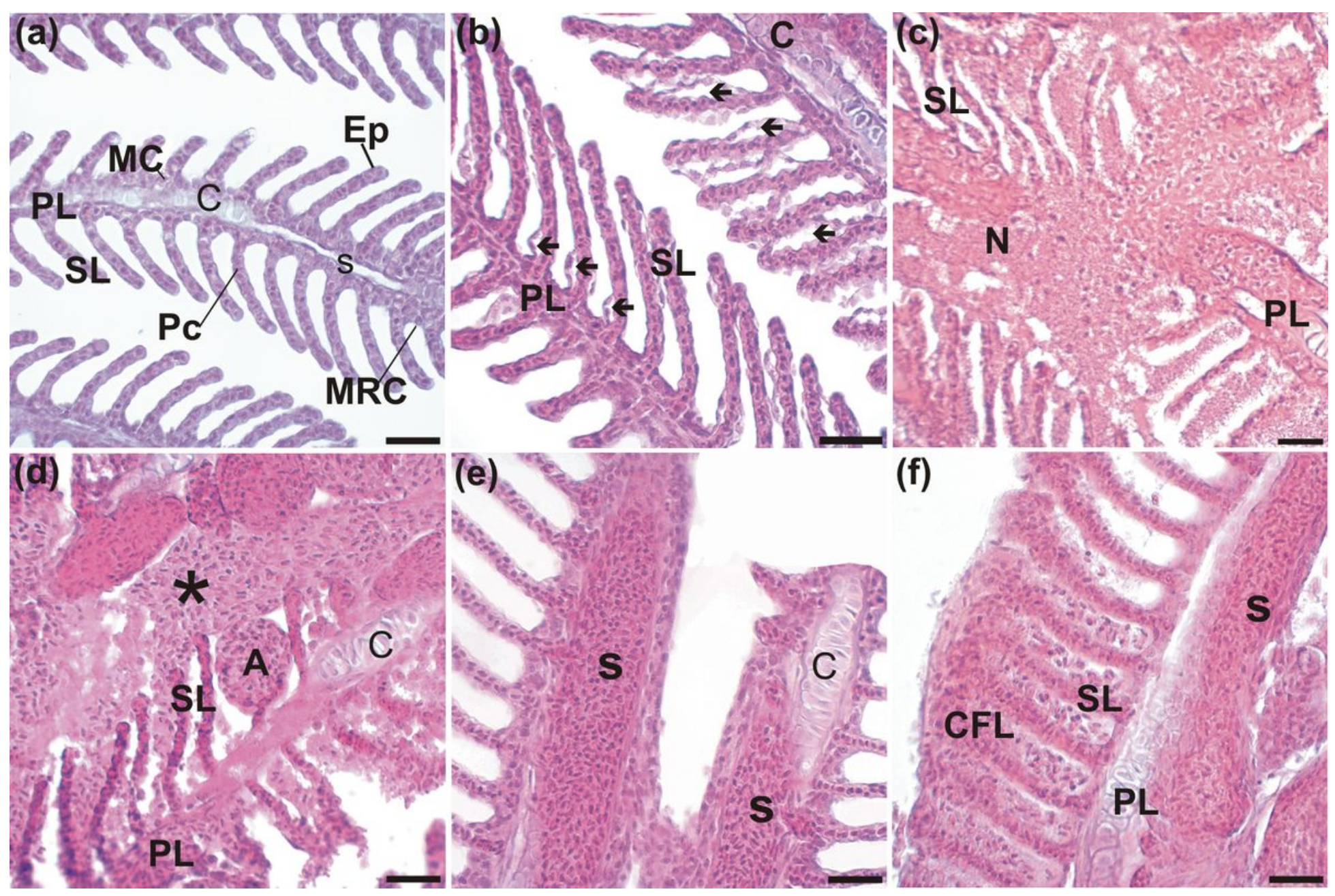

Figure 1

Histological sections of gills from zebrafish stained with Haematoxilin and Eosin (H\&E). (a) control group showed gills with normal histological architecture. $\mathrm{PL}$ primary lamellae; $\mathrm{SL}=$ secondary lamellae; $\mathrm{C}=$ hyaline cartilage; $S=$ central venous sinus; $M C=$ mucous cell; $P c=$ pillar cell; $E p=$ squamous epithelial cell; MRC = mitochondria-rich cell. (b) in all treated groups epithelial lifting = arrow was observed. (c) necrotic area $=\mathrm{N}$ in at least one fish from the treated groups; (d) fish treated with SDS plus Roundup showed hemorrhagic area $\left.{ }^{(*}\right)$ and aneurism $=$ A. (e) fish submitted to Roundup with vascular congestion in central venous sinus $=\mathrm{S}$. (f) fish treated with Temephos plus Roundup showed complete fusion of lamellae $=\mathrm{CFL}$. Bars $=50 \mu \mathrm{m}$. 


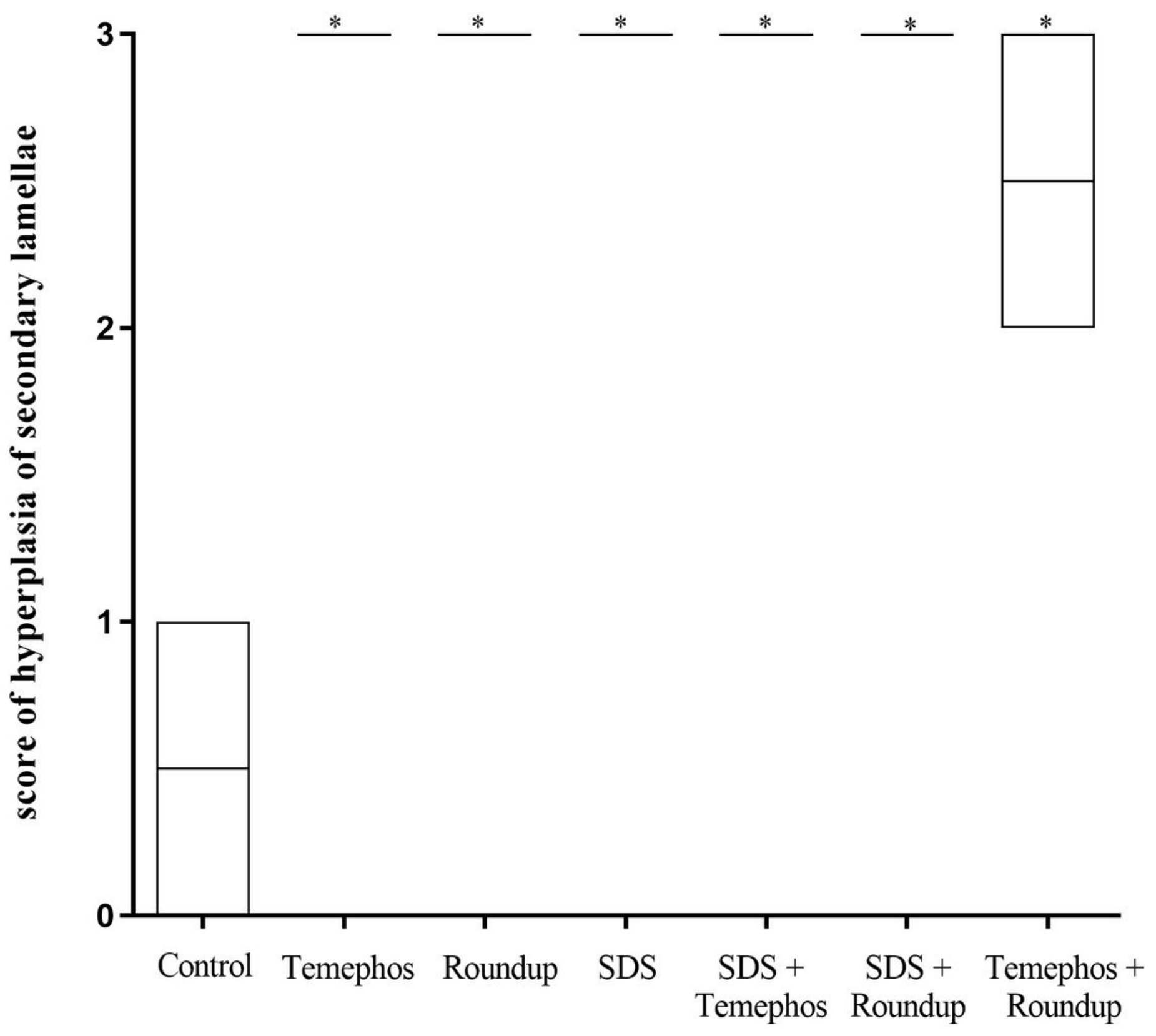

Figure 2

Score of hyperplasia in zebrafish gills. Median score of secondary lamellae hyperplasia observed in gills of zebrafish exposed to Temephos, Roundup, SDS and their combinations. Box represents the median and interquartile range. Bars represents min and max values $(n=4)$. * indicated significant differences compared with control group (Kruskal-Wallis test followed by Dunn's test; $p<0.05$ ). 


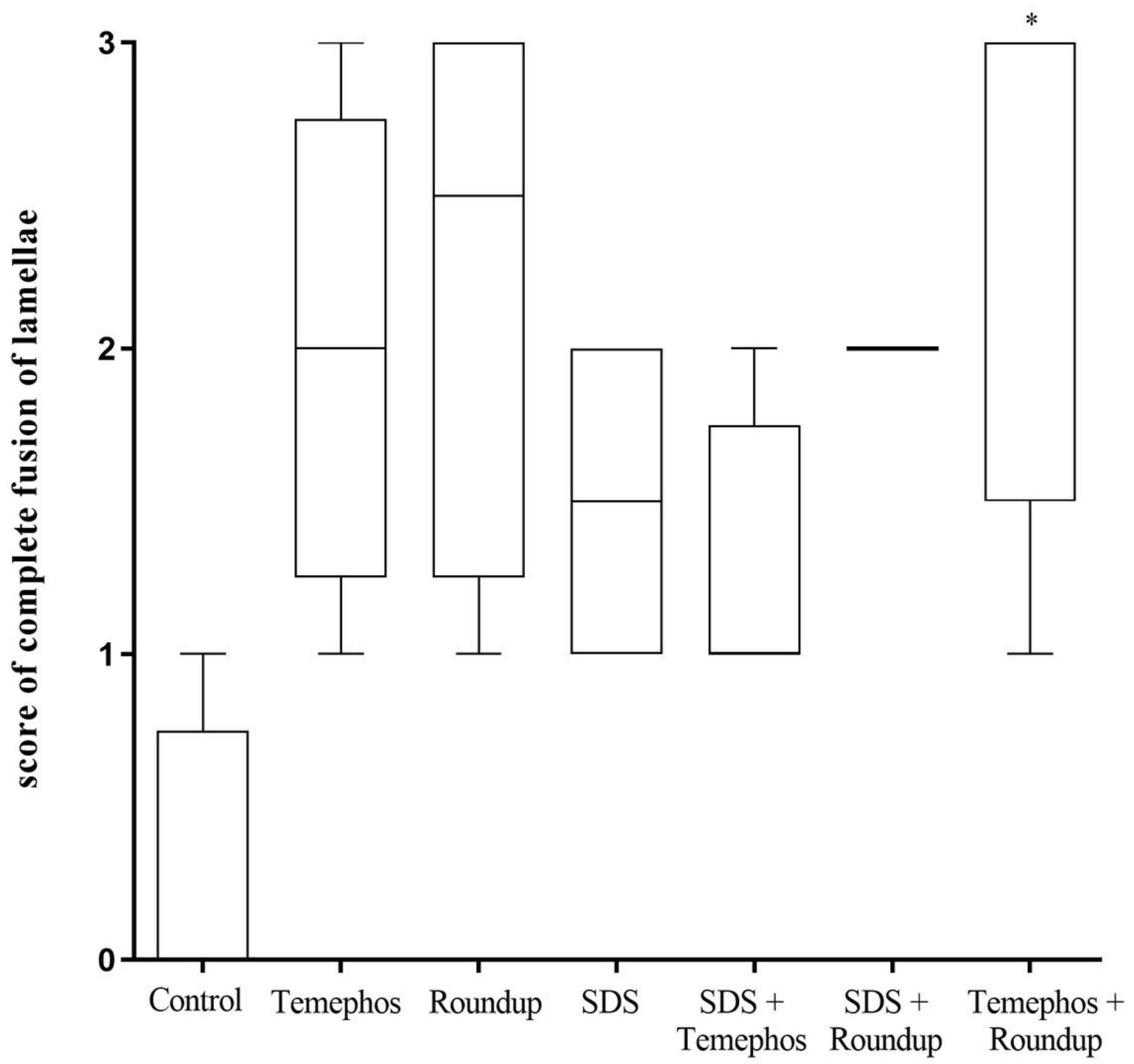

Figure 3

Score of complete fusion of lamellae in zebrafish gills. Median score of complete fusion of some lamellae mean score observed in zebrafish gills exposed to Temephos, Roundup, SDS and their combinations. Box represents the median and interquartile range. Bars represents min and max values $(n=4)$. indicated significant differences compared with control group (Kruskal-Wallis test followed by Dunn's test; $p<0.05)$. 
(A)

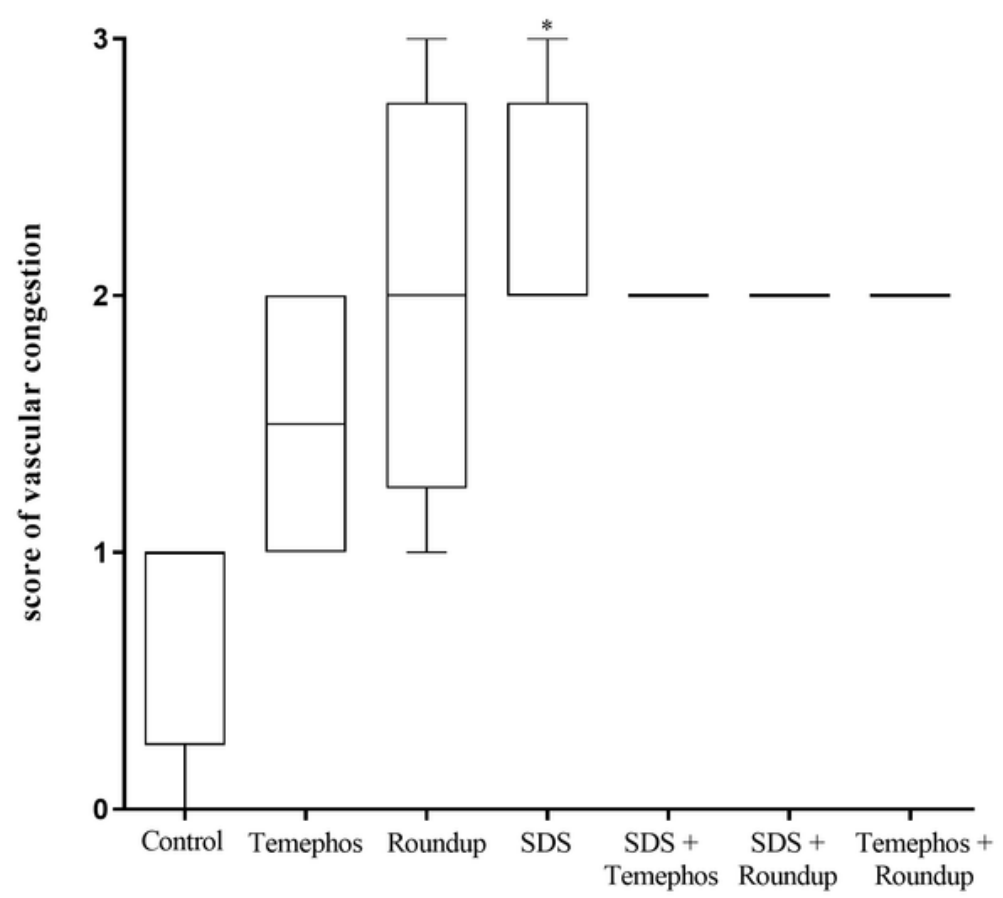

(B)

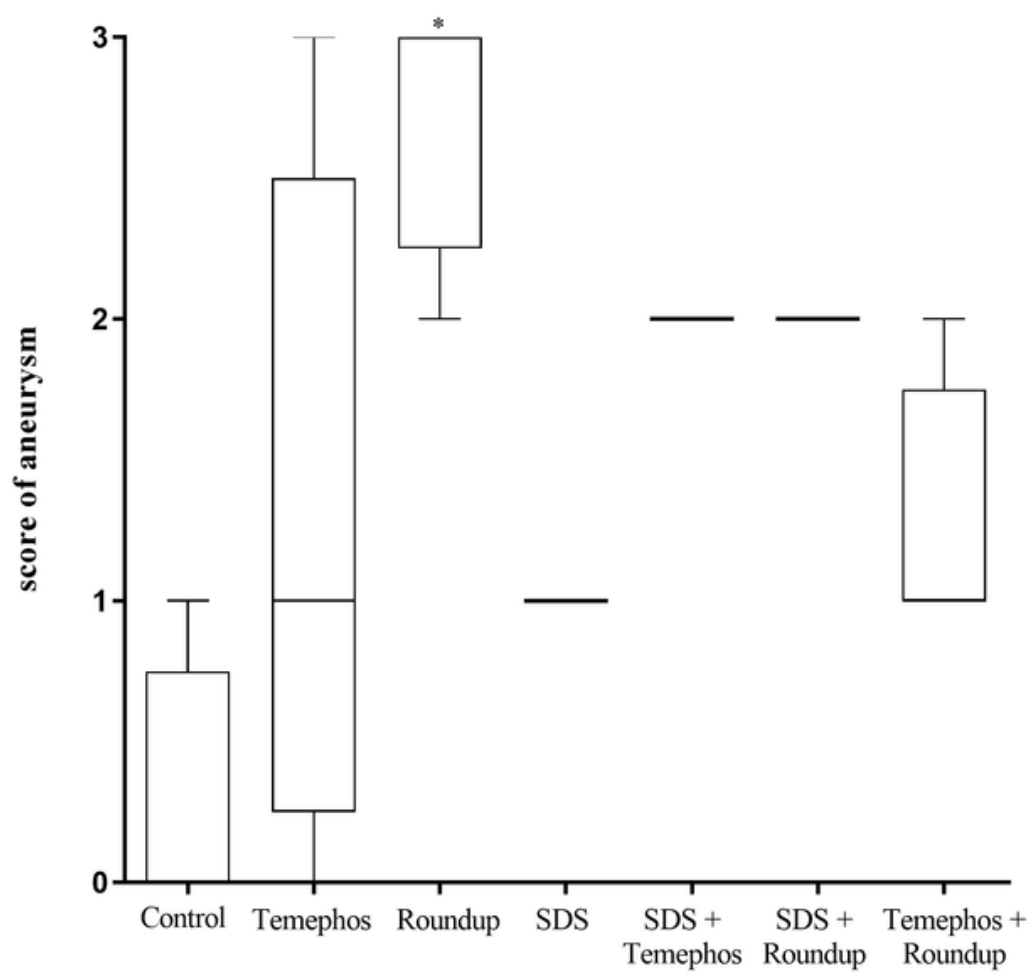

\section{Figure 4}

Score of circulatory disturbances in zebrafish gills. Median score of vascular congestion (a) and aneurism (b) observed in zebrafish gills exposed to Temephos, Roundup, SDS and their combinations. Box represents the median and interquartile range. Bars represents min and max values $(n=4)$. * indicated significant differences compared with control group (Kruskal-Wallis test followed by Dunn's test; $p<$ 0.05). 